\title{
Pengaruh Model Pembelajaran SETS (Science, Environment, Technology and Society) Terhadap Hasil Belajar Biologi Siswa Kelas VII SMP Kartika V-1 Balikpapan Tahun Pelajaran 2015/2016
}

\author{
Euis Yuniastuti \\ Fakultas Ilmu Keguruan dan Ilmu Pendidikan, Universitas Tridharma Balikpapan \\ Jalan A.W. Syahrani Nomor 7, Balikpapan
}

\begin{abstract}
This research aims at investigating the influence of SETS learning model to learning outcomes of Biology subject of seventh grade students at SMP Kartika V-1 Balikpapan academic year of 2015/2016. The research population was 147 seventh grade students of SMP Kartika V-1 Balikpapan, from which 38 students were selected as the research samples. Data collection involved literature study, documentations, field observations, and tests. The data were initially analyzed through an estimation of Karl Pearson's product moment correlation coefficient, from which $r_{\text {hit }}\left(r\right.$-calculated) was obtained and further compared with $r_{\text {tab }}(r$ from statistical table) at two significance levels (5 and $1 \%$, respectively). The results showed that $r_{\text {hit }}>r_{\text {tab }}$, meaning that the correlation was significant. The correlation was also categorized "high" since its value fell in the range of 0,600-0,800. Further analysis required t-test to examine the hypothesis. The calculated t-value $\left(t_{\text {hit }}\right)$ was then compared with $t$-value from statistical table at two significance levels (5 and $\left.1 \%\right)$. The results also exhibited that $t_{\text {hit }}>t_{t a b}$, leading to the acceptance of alternative hypothesis $\left(H_{a}\right)$ and the rejection of null hypothesis $\left(H_{0}\right)$. Data analysis eventually concluded that applying SETS as learning model influenced significantly students' learning outcomes in Biology subject. This model fundamentally allows high performing students to develop their skills whilst at the same time students in academic difficulty were assisted in comprehending problems. Lastly it is expected that, through this model, students' learning outcomes of individuals as well as groups will greatly improve.
\end{abstract}

Keywords : SETS Learning Model, Outcomes of Biology

\begin{abstract}
Abstrak
Tujuan yang ingin dicapai dalam penelitian ini ingin mengetahui pengaruh model pembelajaran SETS terhadaphasil belajar Biologi siswa kelas VIISMP Kartika V-1 Balikpapan tahun pelajaran 2015/2016. Populasi dalam penelitian ini adalah seluruh siswa kelas VII SMP Kartika V-1 Balikpapan yang berjumlah 147 orang dan sampelnya adalah 38 siswa. Untuk memperoleh data yang diperlukan dalam penelitian ini penulis menggunakan metode kepustakaan, dokumentasi, observasi dan tes. Setelah data terkumpul penulis mengolahnya dengan menggunakan alat analisis berupa koefisien korelasi product moment dari Karl Pearson dan mendapatkan harga koefisien korelasir ${ }_{\text {hit }}$ dibandingkan kemudian denganr $_{\text {tab }}$ pada taraf signifikansi $5 \%$ dan $1 \%$. Hasil penelitian menunjukkan bahwar ${ }_{\text {hit }}>r_{\text {tab }}$, sehingga dapat disimpulkan bahwa korelasinya signifikan. Apabila data tersebut dihubungkan dengan tabel interpretasi korelasi termasuk kategori korelasi tinggi karena terletak di antara 0,600-0,800. Selanjutnya dalam pengujian hipotesis dengan menggunakan alat uji-t ( $t$-test) diketahui nilai $t_{\text {hit }}$ dan dihubungkan dengan $t_{\text {tab }}$ pada taraf signifikansi $5 \%$ dan $1 \%$ maka didapat hubungan $t_{\text {hit }}>t_{\text {tab. }}$. Hal ini berarti sesuai dengan kriteria pengujian hipotesis apabila $t_{\text {hit }}>t_{\text {tab }}$ maka menerima hipotesis alternatif $\left(H_{a}\right)$ dan menolak hipotesis nol $\left(H_{0}\right)$. Hasil analisis data menyimpulkan bahwa terdapat pengaruh model pembelajaran SETSterhadap hasil belajar Biologi siswa kelas VII SMP Kartika V-1 Balikpapan Tahun Pelajaran 2015/2016. Dengan demikian, siswa yang pandai dapat mengembangkan kemampuan dan ketrampilannya, sedangkan siswa yang lemah akan terbantu dalam memahami permasalahan yang diselesaikan dalam kelompok tersebut. Dengan demikian diharapkan hasil belajar biologi siswa secara individual maupun kelompok juga akan meningkat.
\end{abstract}

Kata Kunci : Model Pembelajaran SETS ,Hasil Belajar Biologi 


\section{Pendahuluan}

Pada hakikatnya, biologi sebenarnya merupakan pendidikan berorientasi kehidupan, serta lingkungan dan pelaksanaannya sangat dipengaruhi oleh lingkungan masyarakat. Rasanya tidak sesuai jika pembelajaran biologi hanya dilakukan di ruang kelas tanpa adanya kegiatan lapangan. Dengan demikian, guru biologi sangat perlu menguasai materi biologi secara lebih mendalam dengan strategi serta keterampilan mengajar yang baik.

Saat ini, biologi masih diajarkan dengan system hafalan sehingga kurang mengembangkan proses berpikir.Proses pembelajaran siswa dilaksanakan secara pasif (Nuryani, 2005). Seharusnya, pembelajaran biologi yang baik ialah pembelajaran yang dilandaskan pada prinsip keterampilan proses, di mana siswa dididik untuk menemukan dan mengembangkan sendiri fakta dan konsepnya sendiri.

Salah satu upaya yang dapat dilakukan guru untuk meningkatkan pembelajaran agar lebih efektif ialah melalui pendekatan Science, Environment, Technology and Society (SETS). ataudalam bahasa Indonesia dikenal sebagai Sains, Lingkungan, Teknologi, dan Masyarakat. Titik pusat pembelajaran sains berwawasan SETS ialah penggabungan antara konsep sains yang dipelajari dan implikasinya terhadap lingkungan, teknologi dan masyarakat (Binadja, 1999). Keunggulan pembelajaran dengan pendekatan SETS dibandingkan pendekatan lainnya adalah pembelajaran ini selalu dihubungkan dengan kejadian nyata yang dijumpai dalam kehidupan sehari - hari (bersifat kontekstual) dan komprehensif (terintegrasi antara keempat komponen SETS)

Melalui pembelajaran ini, siswa diharapkan memiliki kemampuan menguasai konsep, meningkatkan kreativitas dan kesadaran dalam memahami permasalahan yang berkaitan dengan pelestarian lingkungan. Keterlibatan siswa secara aktif dalam strategi pembelajaran ini dapat membantu mereka memecahkan permasalahan nyata dan merespon secara aktif terhadap fenomena alam di sekitar mereka

Penelitian ini bertujuan mengetahui pengaruh model pembelajaran SETS terhadap hasil belajar biologi siswa kelas VII SMP Kartika V-1 Balikpapan tahun pelajaran 2015/2016

\section{Metode Penelitian}

\section{a) Model pembelajaran SETS}

Pendekatan SETS adalah pendekatan pembelajaran yang berusaha membawa peserta didik agar memiliki kemampuan memandang sesuatu secara terintegratif dengan mengkaitkan keempat unsur SETS sehingga dapat diperoleh pemahaman yang lebih mendalam. Pengetahuan yang dipahaminya secara mendalam itu memungkinkan mereka memanfaatkan pengetahuan yang dimilikinya dalam kehidupan sesuai dengan tingkat pendidikannya. Fokus pengajaran SETS adalah mengenai bagaimana cara membuat peserta didik dapat melakukan penyelidikan untuk mendapatkan pengetahuan sains, lingkungan, teknologi, dan masyarakat yang saling berkaitan. Meminta peserta didik melakukan penyelidikan berarti memberi kesempatan kepada mereka untuk mengembangkan lebih jauh pengetahuan yang telah diperoleh agar dapat menyelesaikan masalah yang diperkirakan timbul di sekitar kehidupannya (Binadja, 1999). Unsur-unsur SETS tidak dapat dipisahkan satu sama lain, terlepas dari fokus perhatian sesuai situasi dan kondisi terkait. Di bidang pendidikan, yang khususnya menjadi fokus adalah sains. Dengan sains sebagai fokus perhatian, guru dan siswa 
yang menghadapi pelajaran sains dapat melihat bentuk keterkaitan dari ilmu yang dipelajarinya (sains) dikaitkan dengan unsur lain SETS. Keterkaitan antara unsur SETS dengan sains sebagai fokus perhatian ditunjukkanoleh Gambar 1

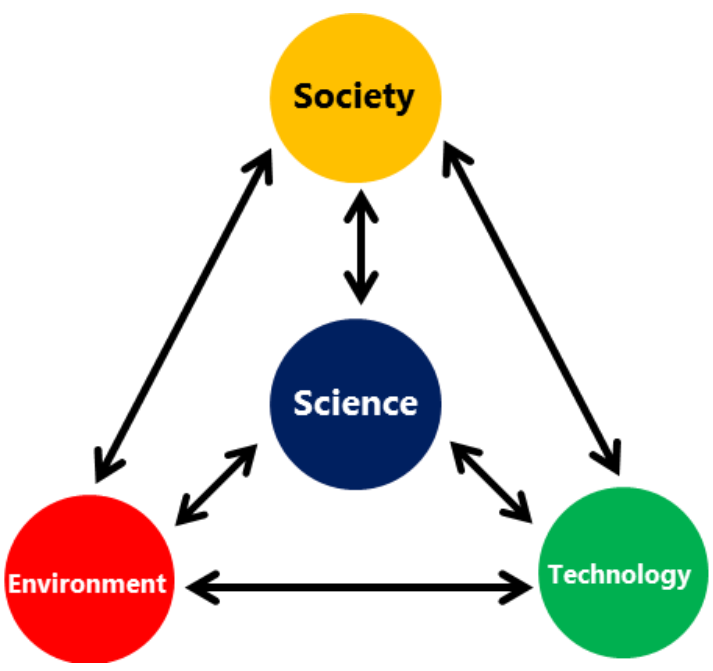

Gambar 1. Hubungan unsur-unsur SETS dengan fokus pada sains

Pendekatan SETS menjelaskan bahwa keempat elemen utama SETS dapat saling memberi dalam hal positif dan negatif. Apabila siswa terbiasa mengatikan keterkaitan positif dan negatif elemenelemen SETS, maka otak mereka akan selalu berusaha menganalisis kondisi dan mensintesis sesuatu yang baru dan diarahkan pada perolehan kebaikan dalam langkah akhir. Dalam suatu pembelajaran Biologi dengan pendekatan SETS, ada beberapa karakteristik yang perlu ditampilkan dalam pembelajaran antara lain:

- tetap memberi pelajaran sains Biologi

- siswa diarahkan untuk memanfaatkan konsep sains Biologi ke dalam bentuk teknologi untuk kepentingan masyarakat sebagai pengguna teknologi

- siswa diminta untuk menjelaskan keterhubungan antarunsur sains Biologi dengan unsur-unsur lain dalam SETS
- siswa diajak untuk mencari dampak kerugian (bila ada) yang ditimbulkan oleh penerapan sains ke bentuk teknologi tersebut terhadap lingkungan dan masyarakat dan mencari teknologi yang lebih baik)

- siswa diajak berdiskusi tentang SETS berkaitan dengan konsep sains yang diajarkan dari berbagai macam arah dan dari berbagai macam titik awal bergantung pada pengetahuan dasar yang dimiliki siswa (Binadja, 1999)

\section{b) Definisi operasional}

Variabel bebasdalam penelitian ini adalah model pembelajaran SETSsedangkat variabel terikat dalam penelitian ini ialah hasil belajar biologi siswa, meliputi nilai biologi yang dicapai oleh siswa pada saat mengerjakan soal pre-test (sebelum menggunakan model belajar SETS) dan soal post-test (setelah menggunakan metode belajar SETS)

\section{c) Populasi dan sampel penelitian}

Populasi penelitian ini adalah seluruh siswa kelas VII SMP Kartika V-1 Balikpapan yang berjumlah 5 kelas (150 siswa). Sampel dalam penelitian ini diambil menurut Arikunto (2006: 134), yaitu apabila subjeknya kurang dari 100 maka sampel diambil semua. Jika jumlah populasinya besar dapat diambil antara10$15 \%$ atau 20-25\% atau lebih. Berdasarkan keterangan tadi dan mengingat populasi di SMP Kartika V-1sebesar 147 siswa (4 kelas) maka sampel yang diambil peneliti berkisar antara $20 \%-25 \%$ dari jumlah populasi. Teknik penarikan sampel diambil secara acak (randomsampling) dengan caraundian untuk mencari kelas yang akan dijadikan sampel

\section{d) Teknik pengumpulan data}

Dalam penelitian ini penulis menggunakan beberapa metode untuk mengumpulkan data yakni metode kepustakaan 
(mengumpulkan data teoritis dari bukubuku referensi), metode dokumentasi (mengumpulkan data dari sekolah yang sudah diarsipkan), metode observasi (mengadakan pengamatan langsung pada obyek yang diteliti.misalnya keadaan dan kegiatan siswa di kelas) dan metode tes yaitu menggunakan pre-test dan post-test. Materi yang diajarkan ialah mengenai Pencemaran Lingkungan.

\section{e) Teknik analisis data}

Penelitian ini menggunakan alat analisis berupa koefisien korelasi productmoment dari Karl Pearson dengan rumus sebagai berikut (Sugiono, 2006: 21):

$$
r_{x y}=\frac{N \sum X Y-\left(\sum X\right)\left(\sum Y\right)}{\sqrt{\left.\left\{N \sum X^{2}-\left(\sum X\right)^{2}\right\} N \sum Y^{2}-\left(\sum Y\right)^{2}\right\}}}
$$

dengan $r_{x y}=$ korelasi antara variabel $x$ dany; $\sum X=$ jumlah nilai variabel $x ; \sum Y=$ jumlah nilai variabel $y ; \sum X Y=$ jumlah hasil kali nilai variabel $x$ dan $y ; \sum X^{2}=$ jumlah kuadrat nilai variabel $x$; dan $\sum Y^{2}=$ jumlah kuadrat nilai variabel $y . x$ dan $y$ mewakili nilai post-test sebelum perlakuan dengan metode SETS dan nilai post-test sesudah perlakuan dengan metode SETS. Nilai korelasi yang didapat diinterpretasikan menurut Tabel 1

Tabel 1. Interpretasi Korelasi (Sutrisno, 1985)

\begin{tabular}{|l|l|}
\hline Nilai korelasi & Interpretasi \\
\hline $0,800<r \leq 1,000$ & Sangat Tinggi \\
\hline $0,600<r \leq 0,800$ & Tinggi \\
\hline $0,400<r \leq 0,600$ & Sedang \\
\hline $0,200<r \leq 0,400$ & Rendah \\
\hline $0,000<r \leq 0,200$ & Sangat Rendah \\
\hline
\end{tabular}

Setelah itu untuk menguji hipotesis dalam penelitian ini digunakan alat uji berupa $t$ test dengan rumus sebagai berikut (Sutrisno, 1985): $t=\frac{r \sqrt{N-2}}{\sqrt{1-r^{2}}}$

dengan $t=$ nilai $t$ hitung $\left(t_{\text {hit }}\right) ; r=$ nilai korelasi variabel $x$ dan $y$; dan $N=$ jumlah sampel.

Langkah-langkah pengujian hipotesis meliputi:

- Hipotesis nol $\left(H_{0}\right)$

Tidak ada pengaruh model pembelajaran SETSyang signifikan terhadap hasil belajar Biologi siswa kelas VII SMP Kartika V-1 Balikpapan tahun pelajaran 2015/2016. Hipotesis ini diterima apabila $t_{\text {hit }}<t_{\text {tab }}$ dan ditolak apabila $t_{\text {hit }}>t_{\text {tab }}$

- Hipotesis alternatif $\left(H_{\mathrm{a}}\right)$

Ada pengaruh model pembelajaran SETS yang signifikan terhadap hasil belajar Biologi siswa kelas VII SMP Kartika V-1 Balikpapan tahun pelajaran 2015/2016. Hipotesis ini diterima apabila $t_{\mathrm{hit}}>t_{\mathrm{tab}}$ dan ditolak apabila $t_{\text {hit }}<t_{\text {tab }}$

\section{Hasil Penelitian dan Diskusi}

Gambar 2 menyimpulkan hasil post-test pada masing - masing dua perlakuan, yaitu sebelum (variabel $x$ ) dan sesudah (variabel $y$ ) diberi model pembelajaran SETS. Berdasarkan data dalam Gambar 2,sebaran nilai pada siswa diketahui sebagai berikut: 


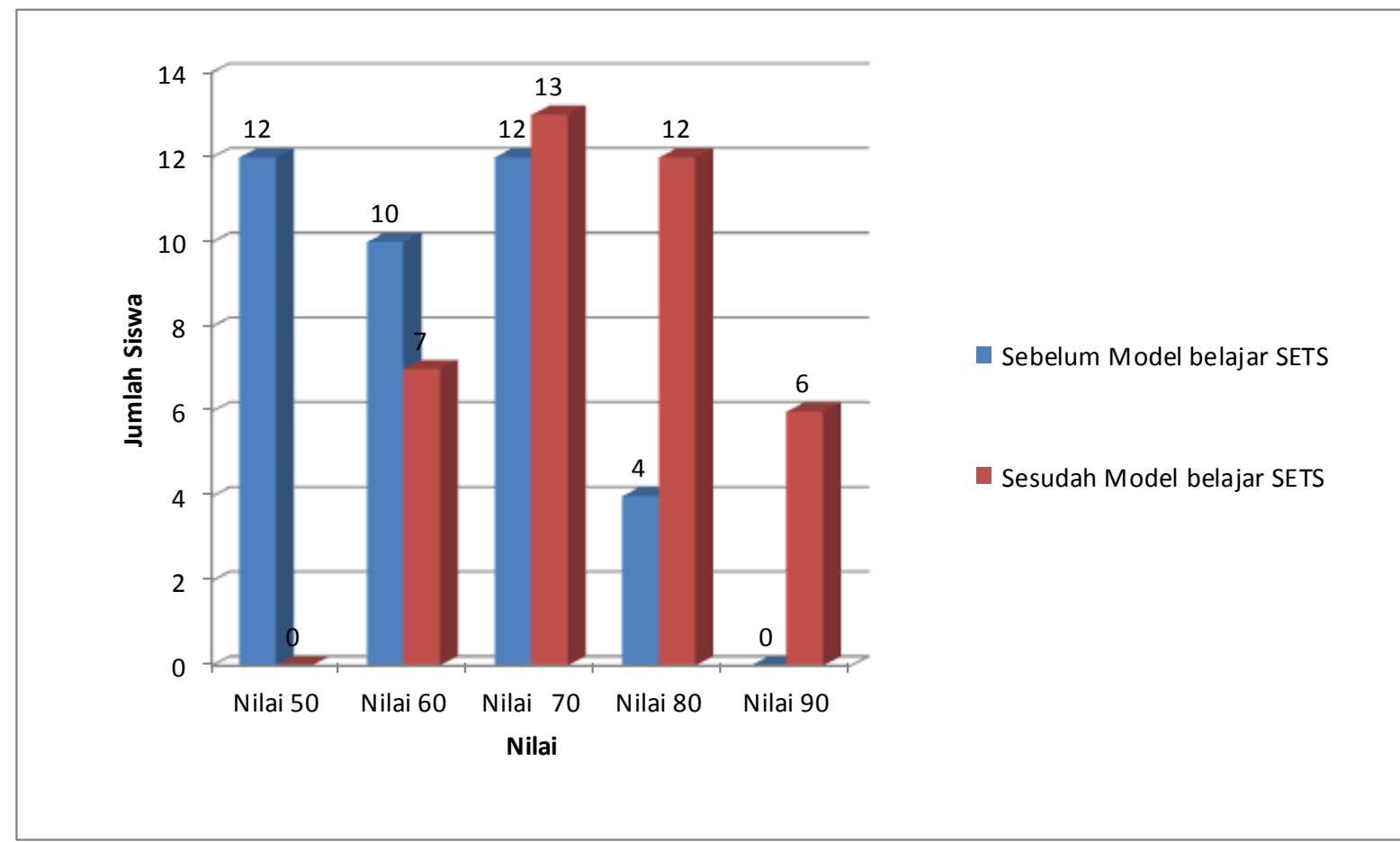

Gambar 2. Sebaran nilai post-test siswa sebelum dan sesudah model belajar SETS

Sebelum model belajar SETS diterapkan, siswa yang mendapat nilai 80 sebanyak 4 orang; siswa yang mendapat nilai 70 sebanyak 12 orang; yang mendapat nilai 60 sebanyak 10 orang; dan yang mendapat nilai 50 sebanyak 12 orang. Sesudah model belajar SETS diterapkan, siswa yang mendapat nilai 90 sebanyak 6 orang; siswa yang mendapat nilai 80 sebanyak 12 orang; yang mendapat nilai 70 sebanyak 13; dan yang mendapat nilai 60 sebanyak 7 orang.

Dari data di atas, dapat diketahui pula beberapa parameter tambahan, $N=38, \sum X$ =2360, $\sum Y=2830, \sum X Y=178600, \sum X^{2}=$ 150400, $\sum Y^{2}=214300$. Koefisien korelasi productmoment dari Karl Pearsondiketahui sebesar 0,77. Jadi, dapat diketahui bahwa antara model pembelajaran SETS terhadap hasil belajar Biologi pada materi pencemaran siswa kelas VII SMP Kartika V-1Balikpapan mempunyai korelasi yang termasuk dalam kategori tinggi, yaitu $\mathrm{r}=$ 0,77 (terletak pada interval $0,600-0,800$ ). Uji hipotesis melalui rumus t-test memperoleh nilai $t_{\text {hit }}$ sebesar 6,58.
Dari hasil penelitian diketahui $r_{\text {hit }}$ sebesar 0,77.Hal ini berarti model pembelajaran SETS dan hasil belajar biologi siswa mempunyai korelasi yang tinggi (berada di antara interpretasi korelasi $0,600-0,800$ ). Nilai $r_{\text {hit }}$ bila kita bandingkan dengan $r_{\text {tab }}$ $(0,32$ pada taraf signifikansi $5 \%$ dan 0,41 pada taraf signifikansi $1 \%$ ) makar $r_{\text {hit }}>r_{\text {tab }}$.Hal ini menunjukkan adanya korelasi yang signifikan antara model pembelajaran SETSdengan hasil belajar biologi di mana siswa termotivasi untuk belajar Biologi khususnya materi pencemaran.

Dalam pembelajaran SETS, siswa mendalami dan mengalami sendiri pengetahuan yang dicarinya sehingga pengetahuan itu akan tetap diingat. Selain itu, siswa dapat mengembangkan daya berpikirnya sendiri, daya inisiatif, daya kreatif, tanggung jawab dan mampu bekerja sama dengan temannya. Adanya korelasi yang tinggi antara model belajar SETS terhadap hasil belajar Biologi siswa kelas VII SMP Kartika V-1 Balikpapan dapat dilihat pada Gambar 2; sebelum 
menggunakan model belajar SETS masih ada siswa yang mendapat nilai 50 sebanyak 31,6\% sedangkan pembelajaran dengan model SETSnilai siswa paling rendah 60 . Bila menggunakan standarisasi kompetensi dasar Biologi di SMP Kartika V-1 Balikpapan, yaitu 60, maka siswa yang sudah mengalami model belajar SETS yang memiliki nilai yang memenuhi nilai kompetensi dasar Biologi adalah $100 \%$ sedangkan pembelajaran yang tidak mengalami model SETS, siswa yang memenuhi standar nilai kompetensi dasar hanya $68,4 \%$.

Dari hasil penelitian di atas juga diperoleh nilai $t_{\text {hit }}$ sebesar 6,58. Adapun $t$ tab diketahui sebesar 2,02 pada taraf signifikansi $5 \%$ dan sebesar 2,70 pada taraf signifikansi $1 \%$. Berdasarkan kriteria pengujian, apabila $t_{\mathrm{hit}}>t_{\mathrm{tab}}$ maka $H_{\mathrm{a}}$ diterima dan $H_{0}$ ditolak. Hal ini menunjukkan bahwa model pembelajaran SETS mempunyai pengaruh yang signifikan terhadap hasil belajar Biologi siswa kelas VII semester II SMP Kartika V-1 Balikpapan pada materi pencemaran tahun ajaran 2015/2016. Meningkatnya hasil belajar Biologi siswa pada materi pencemaran ini disebabkan mereka belajar dalam suasana yang lebih menyenangkan. Mereka dapat mengembangkan kreativitas melakukan penyelidikan langsung ke lingkungan secara bebas tanpa tekanan dari guru. Mereka bekerja sama dengan teman - temannya sehingga memupuk rasa persahabatan dan kesetiakawanan sosial.

Kegiatan penyelidikan tentang pencemaran lingkungan dengan mengaitkan unsurunsur SETS dimaksudkan agar siswa mengetahui, melihat dan merasakan sendiri penyebab serta dampak pencemaran lingkungan, kemudian berpikir kearah membangun dan menghindari ke arah perusakan lingkungan. Hal ini didukung oleh pendapat Sholahudin (2011) bahwa penanaman sikap positif siswa terhadap lingkungan dapat dilakukan jika proses belajar mengajar IPA melibatkan berbagai metode mengajar khususnya eksperimen. Sedangkan menurut Binadja (1999), meminta peserta didik melakukan penyelidikan berarti memberi kesempatan pada mereka untuk mengembangkan lebih jauh pengetahuan yang mereka peroleh agar menyelesaikan masalah yang akan timbul disekitar kehidupannya.

\section{Kesimpulan}

Terdapat pengaruh yang signifikan antara model pembelajaran SETS terhadap hasil belajar Biologi siswa kelas VII semester II SMP Kartika V-1 Balikpapan pada materi pencemaran tahun ajaran 2014/2015. Besarnya pengaruh ditunjukkan oleh nilai koefisien korelasi, $r_{\text {hit }}=0,77$ yang termasuk dalam kategori tinggi. Kemudian diperoleh pula nilai $t_{\text {hit }}$ sebesar 6,58 yang dibandingkan dengan $t_{\text {tab }}$ sebesar 2,02 pada taraf signifikansi $5 \%$ dan sebesar 2,70 pada taraf signifikansi $1 \%$. Berdasarkan kriteria pengujian apabila $t_{\mathrm{hit}}>t_{\mathrm{tab}}$, maka $H_{\mathrm{a}}$ diterima dan $H_{0}$ ditolak.

\section{Daftar Pustaka}

Arikunto, Suharsimi. 2006. Prosedur Penelitian Suatu Pendekatan Praktek. Jakarta: Rineksa Cipta

Binadja, A. 1999. Hakekat dan Tujuan Pendidikan SETS dalam Konteks Kehidupan dan Pendidikan yang Ada. Makalah Semiloka Pendidikan SETS. RECSAM UNNES. Semarang $14-15$ Desember 1999

Nuryani. 2005. Strategi Belajar Mengajar Biologi. Malang: UM Press

Sholahudin A. 2001. Pemberdayaan Pembelajaran IPA dalam Upaya Menumbuhkan Sikap Positif Terhadap Lingkungan. Jakarta: http/www.tut0r Sugiono.2006. Statistik Untuk Penelitian. Bandung: CV Alfa Beta

Sutrisno, Hadi.1995. Metodologi Research. Yogyakarta: Penerbit Andi Offset Yogyakarta 


\title{
Analisis Biaya Satuan (Unit Cost) Mahasiswa Berdasarkan Activity Based Costing Pada Politeknik "X” Di Balikpapan
}

\author{
Nur Vita Opu ${ }^{1)}$, Ida Suriana ${ }^{2)}$, Yogiana Mulyani ${ }^{3)}$ \\ Jurusan Tata Boga, Politeknik Negeri Balikpapan \\ Email : nur.vita@poltekba.ac.id \\ Email : ida.suriana@poltekba.ac.id
}

\begin{abstract}
This research is quantitative research. This research is aimed to design the Activity Based Costing and determine Unit Cost of educational services to students per course of study. This research was conducted at Balikpapan State Polytevhnic in 2014. The data collection was done by doing interview, observation and documentation. Unit Cost calculation result is a food and beverage department of Rp25.825.152, - per year, Electrical Engineering Program in Department of Industrial Electronics Engineering of Rp24.080.407, - per year. Department of Telecommunications of Rp24.080.407, - per year. Department of Computer Engineeringand Networks of Rp24.080.407, - per year, Civil Engineering Program of Rp24.795.028, - per year. MechanicalEngineering and Heavy Equipment Rp26.970.795, - per year.
\end{abstract}

Keywords : Unit Cost, Cost of Education, Activity Based Costing

\begin{abstract}
Abstrak
Penelitian ini merupakan penelitian kuantitatif. Penelitian ini bertujuan untuk merancang model pengalokasian berbasis aktivitas (Activity Based Costing) dan mengetahui biaya satuan (Unit Cost) layanan pendidikan kepada mahasiswa per program studi. Penelitian ini dilakukan di Politeknik X Tahun 2014. Pengumpulan data dilakukan dengan cara wawancara, observasi dan dokumentasi. Hasil perhitungan Unit Cost adalah Program Studi Tata Boga Rp25.825.152, - per tahun, Program Studi Teknik Elektro Jurusan Teknik Elektronika Industri Rp24.080.407,- per tahun. Jurusan Telekomunikasi Rp24.080.407,- per tahun. Jurusan Teknik Komputer dan Jaringan Rp24.080.407,- per tahun, Program Studi Teknik Sipil Rp24.795.028,- per tahun. Teknik Mesin dan Alat Berat Rp26.970.795,- pertahun.
\end{abstract}

Kata kunci : Biaya Satuan, Biaya Pendidikan, Biaya berbasis aktivitas

\section{Pendahuluan}

Ekonomi suatunegara dalam jumlah besar tergantung pada industri yang ada, khususnya sektor jasa seperti perusahaan asuransi, lembaga keuangan, pelayanan kesehatan, dan transportasi. Sebagian besar sektor korporasi lebih banyak bertualang ke bidang industri jasa untuk menciptakan persaingan, mereka diwajibkan untuk menyediakan layanan pelanggan berkualitas dengan biaya yang wajar (Krishnan, 2006).

Salah satu bentuk usaha pelayanan jasa adalah pendidikan.Pendidikan merupakan salah satu faktor dalam berkembangnya pembangunan suatu negara.Lembaga pendidikan merupakan salah satu lembaga yang memberikan pelayanan pendidikan sekaligus bertindak sebagai Badan Penyelenggara yang menghasilkan lulusan yang berkualitas sesuai dengan tuntutan dunia kerja.Selain memberi pelayanan pendidikan, lembaga pendidikan juga mengemban tugas sosial, yaitu mengutamakan kepentingan masyarakat dan tidak berorientasi pada keuntungan.

Oleh karena itu lembaga pendidikan termasuk organisasi non profit.Lembaga pendidikan sebagai organisasi non profit 